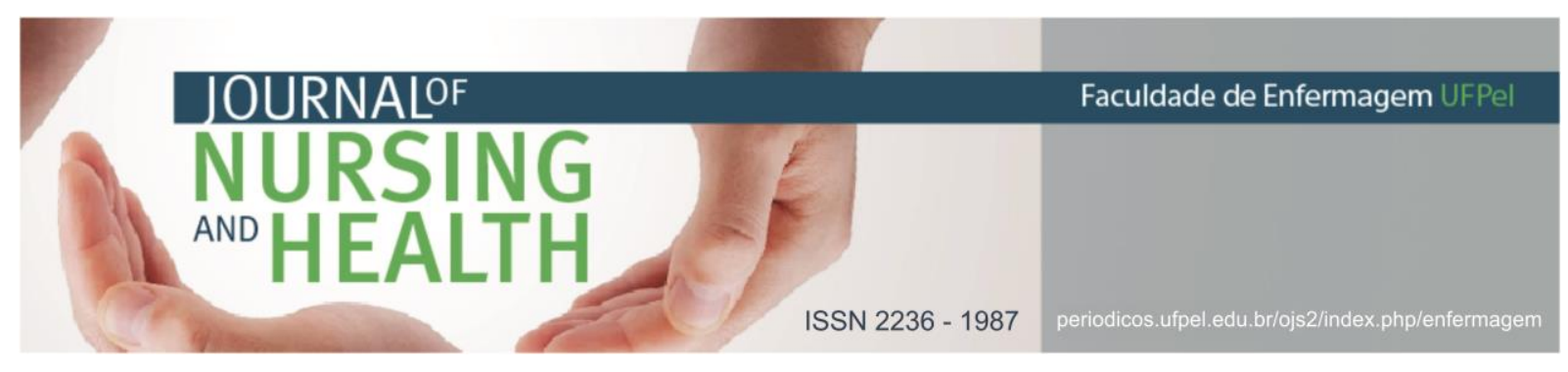

ARTIGO ORIGINAL

\title{
Aprender a cuidar de estoma e as contribuições de um vídeo educativo
}

\author{
Learning to take care of stoma and the contributions of an educational video \\ Aprender a cuidar de estoma y las contribuciones de un video educativo
}

Costa, Tatiana Costa da ${ }^{1}$; Girardon-Perlini, Nara Marilene Oliveira²; Gomes, Joseila Sonego ${ }^{3}$; Dalmolin, Angélica4; Coppetti, Larissa de Carli5; Rossato, Gabriela Camponogara6

Como citar este artigo: Costa, TC, Girardon-Perlini NMO, Gomes JS, Dalmolin A, Coppetti LC, Rossato GC. Aprender a cuidar de estoma e as contribuições de um vídeo educativo. J. nurs. health. 2018;8(3):e188301

\section{RESUMO}

Objetivo: conhecer a percepção de pacientes colostomizados por causas não oncológicas e seus familiares acerca da forma como aprenderam a cuidar do estoma e da possibilidade de utilização de um vídeo educativo como estratégia de educação em saúde. Métodos: pesquisa qualitativa, realizada por meio de grupo focal com oito pessoas, sendo quatro pacientes e quatro familiares. Os dados foram submetidos à análise de conteúdo temática. Resultados: organizou-se três categorias: Aprendendo a cuidar do estoma; o apoio familiar como potencializador do cuidado e da adaptação; as possibilidades e limitações no uso do vídeo educativo. Considerações finais: o processo de aprender a cuidar do estoma foi marcado pela escassez de orientações de enfermagem e concretizado no aprenderfazendo, sendo a colaboração da família importante para o cuidado. 0 vídeo educativo mostra-se como tecnologia útil para educação em saúde, ao apresentar orientações básicas para o cuidado da colostomia, podendo complementar as orientações de enfermagem.

Descritores: Colostomia; Educação em saúde; Tecnologia educacional; Enfermagem; Família

\section{ABSTRACT}

Objective: to know the perception of colostomized patients due to non-oncological cause and their relatives in front of the use of an educational video as a health education strategy. Methods: qualitative research, performed through a focus group with eight people, four patients and four relatives. The data were submitted to the thematic content analysis. Results: three categories were organized: Learning how to take care of and manage the stoma; Acceptance and adaptation: family

1 Enfermeira. Universidade Federal de Santa Maria (UFSM). E-mail: taticostafv@gmail.com http://orcid.org/0000-0002-5161-5238

2 Enfermeira. Doutora em Enfermagem. Universidade Federal de Santa Maria (UFSM). E-mail: nara.girardon@gmail.com http: //orcid.org/0000-0002-3604-2507

3 Enfermeira. Mestre em Enfermagem. Universidade Regional do Noroeste do Estado do Rio Grande do Sul (UNIJUI). E-mail: joseila.sonego@unijui.edu.br http://orcid.org/0000-0002-9873-0006

4 Enfermeira. Universidade Federal de Santa Maria (UFSM). E-mail: angelica_dalmolin@hotmail.com http://orcid.org/0000-0002-0595-1054

5 Enfermeira. Especialista em UTI coronariana e hemodinâmica. Universidade Federal de Santa Maria (UFSM). Email: lari_decarli@hotmail.com http://orcid.org/0000-0002-3162-6669

6 Enfermeira. Universidade Federal de Santa Maria (UFSM). E-mail: gabriela_rossato@yahoo.com.b http: / /orcid.org/0000-0003-4371-0590 


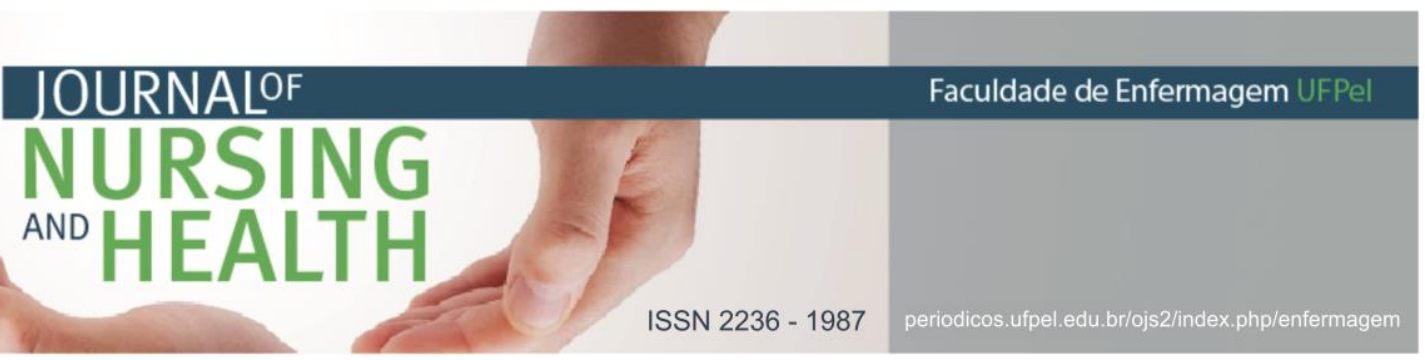

support as a potentiator of this process; Educational video: possibilities and limitations. Final considerations: the process of learning to take care of the stoma was marked by the scarcity of nursing guidelines and made feasible in learning-doing, with family collaboration being important to care. The educational video is a useful technology in the health education process, presenting basic guidelines for colostomy care, and can to complement nursing orientations.

Descriptors: Colostomy; Health education; Educational technology; Nursing; Family

\section{RESUMEN}

Objetivo: conocer la percepción de pacientes colostomizados por causa no oncológica y sus familiares frente la utilización de un video educativo como estrategia de educación en salud. Métodos: investigación cualitativa, realizada por medio de grupo focalcon ocho personas, siendo cuatro pacientes y cuatro familiares. Los datos fueron sometidos al análisis de contenido temático. Resultados: tres categorías: Aprender a cuidar y manejar el estoma; Aceptación y adaptación: el apoyo familiar como potencializador de ese proceso; Vídeo educativo: posibilidades y limitaciones. Consideraciones finales: el proceso de aprender a cuidar del estoma fue marcado por la escasez de orientaciones de enfermería y viabilizado en el aprendizaje-haciendo, siendo la colaboración de la familia importante. El video educativo se presenta como tecnología útil para educación en salud, al presentar orientaciones básicas para el cuidado de la colostomía, pudiendo complementar las orientaciones de enfermería.

Descriptores: Colostomía; Educación en salud; Tecnología educacional; Enfermería; Familia

\section{INTRODUÇÃO}

A estomização intestinal constitui-se na confecção de um orifício na parede abdominal, o qual faz uma comunicação do meio interno com o externo e tem por finalidade 0 desvio do conteúdo fecal, podendo ser temporária ou permanente. Dentre os tipos de estomas intestinais de eliminação encontram-se as ileostomias e as colostomias. A colostomia é um estoma proveniente da remoção da porção do intestino grosso afetado, sendo resultante da terapêutica para o câncer de cólon e reto, doenças inflamatórias do trato intestinal ou traumas colorretais, sendo o tipo de estoma intestinal mais recorrente na população. ${ }^{1}$

O câncer colorretal apresenta-se como a causa predominante para a realização de uma colostomia, seguida das causas congênitas. Algumas doenças inflamatórias como a retocolite ulcerativa, a doença de
Crohn e condições hereditárias, como por exemplo, a polipose adenomatosa familiar, também, apresentam como principal terapêutica, a colostomia. ${ }^{2}$

As pessoas portadoras de um estoma passam a ter seu padrão de eliminação intestinal alterado e enfrentam situações que afetam aspectos fisiológicos, psicossociais e espirituais. $^{3} \quad$ Nessa perspectiva, vivenciam uma realidade decorrente da presença da colostomia, que resulta no uso contínuo de uma bolsa coletora de fezes aderida a parede abdobimal. Essa condição altera a imagem corporal e contribui para suscitar sentimentos conflituosos que podem postergar o processo de adaptação e aceitação da doença e de seu novo jeito de viver. ${ }^{4}$

Tendo em vista as situações de fragilidade experenciadas, tanto pelo paciente, quanto por seus familiares ou, por aqueles que o auxiliam no 


\section{JOURNALOF \\ NURSING \\ AND HEALTH}

ISSN 2236 - 1987

cuidado, torna-se fundamental a utilização de recursos humanos e tecnológicos que visem facilitar o convívio com as adversidades inerentes a colostomia. Sob essa ótica, a assistência de enfermagem precisa englobar a pessoa com estoma e sua família, utilizando ações de educação em saúde para favorecer o cuidado e o autocuidado. ${ }^{5}$

Logo, destaca-se a importância do enfermeiro enquanto educador em saúde no contexto das pessoas estomizadas, uma vez que este se encontra mais próximo do paciente e de sua família, tanto na hospitalização, quanto no retorno ao seu domicílio, fator que favorece o desenvolvimento de ações que fortaleçam o cuidado e contribuam no processo de reabilitação, minimizando possíveis dificuldades. ${ }^{5-6}$

0 profissional enfermeiro dispõe de recursos técnicos, científicos e relacionais para esclarecer dúvidas e acolher anseios advindos da nova realidade, bem como subsidiar o preparo e a capacitação na busca pela autonomia, por meio de ações de educação em saúde. A efetividade dessas intervenções decorre da proximidade estabelecida na relação profissional-paciente-família, a qual pode ser efetivada pela formação do vínculo, ${ }^{6}$ repercurtindo em confiança, segurança $e$ independência para $o$ cuidado.

A complexidade que compõe a especificidade de cuidar das necessidades do paciente com colostomia e de seus familiares, conforma um espaço propício para a utilização de tecnologias educativas, com vistas à construção do saber compartilhado. Dentre as tecnologias utilizadas, destaca-se o uso de vídeos educativos como uma forma de divulgação, socialização do conhecimento e troca de informações, ${ }^{7}$ bem como de promoção da saúde. ${ }^{6}$

A utilização de vídeos educativos, enquanto tecnologia educacional para o cuidado configura uma das formas de expressão da humanização e da ludicidade do fazer na assistência em saúde da enfermagem, assegurando criatividade às orientações e promovendo a atuação críticoreflexiva frente às demandas de cuidado. ${ }^{7}$

Com relação à utilização desse recurso tecnológico, destaca-se estudo que objetivou desenvolver e validar um vídeo educativo para famílias que possuem um membro com colostomia por câncer, haja vista as repercussões provenientes do diagnóstico que se associam as mudanças advindas com a estomização. 0 vídeo desenvolvido foi validado por juízes especialistas e pelo público alvo (famílias de pessoas com um membro portador de colostomia por câncer), sendo reconhecido enquanto uma tecnologia educativa útil no contexto de cuidado da pessoa e da família que vivenciam a colostomia. ${ }^{8}$

A partir dos resultados obtidos no estudo de validação supracitado, entende-se que 0 referido vídeo educativo, ${ }^{8}$ considerando suas potencialidades para favorecer 0 cuidado, o autocuidado e a autonomia da pessoa colostomizada por câncer, possa também se constituir em uma ferramenta de educação em saúde para pacientes colostomizados por situações não oncológicas e para seus 


\section{JOURNALOF \\ NURSING \\ ANO HEALTH}

ISSN 2236 - 1987

saúde à pessoa com estoma e seus familiares.

Os participantes do estudo foram oito pessoas, sendo quatro pessoas com colostomia por situações não oncológicas e quatro familiares envolvidos no cuidado domiciliar que, voluntariamente, aceitaram o convite para participar da pesquisa.

Foram estabelecidos como critérios de inclusão: apresentar idade igual ou superior a 18 anos, conferindo assim, maioridade legal para decidir sobre a participação no estudo; apresentar colostomia, independente do tempo pós-operatório; estar acompanhado de no mínimo um familiar envolvido no cuidado domiciliar. Como critérios de exclusão definiram-se: pacientes portadores de colostomia por câncer e para os familiares foi considerado como critério de exclusão a idade inferior a 18 anos.

Como forma de localizar os possíveis participantes do estudo, foi realizada uma aproximação ao grupo de apoio a pessoas estomizadas do município, o qual tem suas atividades vinculadas a UBS, com participação de aproximadamente 35 pessoas. Essa estratégia facilitou a identificação dos possíveis participantes que correspondiam aos critérios de inclusão e exclusão. Considerando que a época do estudo participava do grupo 10 pessoas com colostomia por causa não oncológica, estas foram convidadas a participar do estudo, sendo esclarecido 0 objetivo da pesquisa e demais aspectos éticos relacionados à voluntariedade, anonimato, riscos e benefícios. Mediante aceite, foi agendando um 
encontro para a realização da atividade grupal conforme a disponibilidade comum de todos os participantes.

A coleta dos dados foi realizada no mês de setembro de 2016, por meio de um formulário com questões sociodemográficas e a realização de um grupo focal. Destaca-se que o encontro para a produção dos dados foi confirmado previamente, conforme acordado com os participantes.

O grupo focal é uma forma de entrevista em grupo, orientado por um guia de temas, o qual permite a comunicação e a relação entre as pessoas, de modo que a informação não seja transmitida em sentido unilateral, caracterizando-se como um processo de interação e troca de ideias entre as diferentes realidades que compõem o grupo. 0 objetivo precípuo desta estratégia é estimular a reação de todos os participantes diante das falas uns dos outros, permitindo com isso um movimento recíproco e participativo, influenciado pela natureza social da interação do grupo. ${ }^{9}$

A realização do grupo focal compreende três fases, das quais é imprescindível a participação de um moderador e de observadores que possuem papel ímpar na realização do grupo, contribuindo com diferentes tarefas. O moderador faz o papel de mediador do grupo, conduz a realização do mesmo e estimula os participantes a dialogar sobre o tema em discussão. Os observadores registram as interações não verbais $e$ controlam o tempo da atividade. ${ }^{9}$

Neste estudo, o grupo focal contou com a participação de um moderador e dois observadores. 0 ambiente para a realização do grupo focal foi pensado e organizado antecipadamente, objetivando acolher os participantes, sendo as cadeiras dispostas em círculo, com vistas a facilitar a interação grupal e permitir o contato visual entre os participantes. A sala foi reservada exclusivamente para essa finalidade, no intento de evitar interrupção durante desenvolvimento da atividade.

Seguindo as três fases preconizadas na realização de um grupo focal, no primeiro momento foi realizada uma dinâmica de apresentação, em que os participantes foram convidados a se apresentar com nome e uma característica pessoal que considerassem pertinente para o momento. Essa dinâmica de apresentação permitiu o envolvimento e a aproximação entre os membros do grupo.

$\mathrm{Na}$ segunda fase concebeu-se a coleta de dados propriamente dita. Introduziu-se a conversa por meio do guia de temas, sendo organizado em quatro pontos temáticos. 0 primeiro ponto tratava sobre o cuidado com o estoma em cinco perguntas detalhadas acerca do assunto, foram elas: como aprendeu a cuidar?; com quem aprendeu?; onde aprendeu?; quando aprendeu?; e o que ajudou? As temáticas foram disparadas pelo moderador a fim de facilitar a discussão em grupo.

Após esta etapa, ainda na segunda fase de desenvolvimento do grupo focal, foi realizada a exibição do vídeo educativo desenvolvido, o qual aborda as principais orientações acerca dos cuidados para higienização 
ISSN 2236 - 1987

e manuseio do estoma e da bolsa coletora, orientações básicas direcionadas a alimentação do paciente com colostomia e depoimentos encenados por atores, que simulam situações de vida do paciente e de familiares que vivenciam a colostomia, intencionando encorajar e tornar mais cooperativa e solidária a adaptação da família diante da colostomia. 0 vídeo tem duração de oito minutos e 35 segundos, constituído de recurso auditivos e visuais que permitem ao espectador contextualizar e familiarizar-se com os cuidados e produtos utilizados no manejo com o estoma.

Outro ponto abordado na segunda fase do grupo focal direcionou-se a avaliação do vídeo, considerando sua viabilidade enquanto recurso de educação em saúde, detalhado em perguntas relacionadas à tecnologia audiovisual utilizada. Nesse sentido, os participantes foram instigados a dialogar acerca da utilidade do vídeo enquanto um recurso para a educação em saúde, nas situações oriundas pela confecção de um estoma por causas não oncológicas. Além disso, foram feitas as seguintes indagações: o que vocês pensam sobre a linguagem utilizada?; o conteúdo do vídeo?; tempo de duração?; a dinâmica utilizada no vídeo? Ademais, os participantes também foram estimulados a comentar sobre as fragilidades/singularidades da tecnologia audiovisual.

A terceira e última fase da realização da dinâmica do grupo focal foi direcionada a finalização da atividade e aos agradecimentos, sendo, então, oferecido um chá para a confraternização dos participantes. A dinâmica teve duração de aproximadamente 80 minutos. As falas provenientes do grupo focal foram gravadas em sua totalidade e, após transcritas na íntegra para serem submetidas à análise de conteúdo, em torno de três polos cronológicos. ${ }^{10}$

O primeiro polo é a pré-análise do material, fase de organização dos dados para tornar operacionais e sistematizar as ideias inicias. 0 segundo polo compõe a exploração do material, sendo a fase mais longa e minuciosa, com operações de codificação, decomposição ou enumeração e conformação de possíveis categorias. 0 último polo é o de tratamento e interpretação dos resultados, em que o material oriundo da coleta de dados é tratado de maneira significativa e válida, constituindo as categorias do estudo. Finalizando o processo de análise os resultados encontrados foram discutidos com base em referencial de cotejamento. ${ }^{10}$

Respeitando os aspectos éticos, a pesquisa foi aprovada por Comitê de Ética em Pesquisa sob parecer $n^{\circ}$ 1.461.655. Todos os participantes assinaram o Termo de Consentimento Livre e Esclarecido. O anonimato da identidade dos participantes do estudo foi assegurado por códigos de identificação alfanuméricos (P1, F1; P2, F2; P3, F3 e P4, F4), em que a letra "P" refere-se a paciente e a letra " $F$ " o familiar.

\section{RESULTADOS E DISCUSSÃO}

Dos oito participantes do estudo, quatro eram pessoas portadoras de colostomia, sendo três do sexo 
masculino, colostomizados por ferimento de arma de fogo e um do sexo feminino, colostomizada por doença de Crohn, com idade de 32, 40, 48 e 66 anos. Quanto ao estado civil, um dos participantes era separado e três eram casados. 0 tempo de realização do estoma variou de quatro meses a um ano. Quanto à escolaridade, dois possuem ensino fundamental incompleto, um ensino fundamental completo e um ensino médio completo.

Os quatro familiares que se envolviam nos cuidados domiciliares eram do sexo feminino, cônjuges (duas), filha(uma) e sobrinha (uma), com idades de 24, 26, 30 e 59 anos. Como profissão, uma era do lar, uma empregada doméstica, uma era estudante e a outra recepcionista. Com relação à escolaridade, duas têm ensino fundamental incompleto, uma tem ensino técnico e uma graduação em desenvolvimento.

Após a leitura exaustiva do material proveniente da coleta de dados, o conteúdo expresso foi agrupado por similaridade e discordância de informações, emergindo três categorias de análise: Aprendendo a cuidar do estoma; 0 apoio familiar como potencializador do cuidado e da adaptação e As possibilidades e limitações no uso do vídeo educativo.

\section{Aprendendo a cuidar do estoma}

Aprender a cuidar do estoma é um processo em que o paciente com colostomia e sua família podem encontrar algumas dificuldades, tanto no que tange ao cuidado dispensado pelos familiares, quanto no autocuidado e na realização das atividades diárias de vida. Essa necessidade emerge no pós-operatório imediato e está associada às transformações fisiológicas do corpo, decorrentes do desvio do trânsito intestinal, e das repercussões nas esferas emocional e social das pessoas.

Diante da necessidade de cuidados com o estoma e ante as mudanças advindas da nova realidade, desafios a serem superados pelos pacientes e por suas famílias se apresentam. Nesse contexto, as orientações educativas de enfermagem constituem-se como um elemento potencializador para assimilação do funcionamento do corpo e apropriação das demandas de cuidado a serem realizadas. ${ }^{4}$

Contudo, as falas dos participantes revelam a insuficiência de orientações como um fator que posterga a compreensão e a adaptação a partir da confecção do estoma, dificultando o cuidado e o autocuidado a ser realizado no domicílio.

Quando ele saiu do hospital, eu não tive orientação de um profissional para me dizer exatamente como eu deveria fazer. Teria sido importante se eu tivesse sido orientada, pois melhoraria a qualidade do tratamento. Mas eu não tive orientação nenhuma. (F2)

Eram as enfermeiras que trocavam a bolsa. Elas nunca me disseram como tinha que fazer. Elas vinham e trocavam para mim, depois eu ia ao banheiro e lavava. (P4) 


\section{IOURNALOF

A carência de informações e orientações educativas por parte da enfermagem influencia significativamente no processo de aprendizagem para o cuidado e o autocuidado, repercutindo em dificuldade para a execução de atividades que podem ser consideradas simples, como a troca e a higienização da bolsa coletora. Nesta perspectiva, somado a insegurança advinda do contexto vivenciado, a redução do período de internação hospitalar no pós-operatório, que, por vezes, limita o desenvolvimento de ações educativas ao paciente e sua família, tendem a tornar o regresso ao domicílio e o cuidado e autocuidado uma tarefa desafiadora. ${ }^{11}$

Ante a insuficiência de orientações, os pacientes e seus familiares buscam estratégias que subsidiem a execução das atividades de cuidado, como a observação dos procedimentos realizados durante a hospitalização e na unidade básica de saúde. Também, buscam na internet informações que ajudem a suprir as demandas para cuidado da colostomia no domicílio.

Não recebi informações de cuidado no hospital. Quando eu fiz a ficha no posto, eu pegava duas, três bolsas e levava para casa. Eram as enfermeiras do posto que trocavam, mas elas nunca me disseram faz assim ou assim. Eu fui olhando e pegando o jeito. (P3)

A troca e a higienização foram feitas por mim. Eu fui olhando e lendo, olhando alguma coisa na internet, e é como eu tenho feito. Eu descobri sozinha. E é como faço até hoje. (F4)

\section{A gente se adapta aos problemas e vai se moldando, vai aprendendo aos poucos. (P2)}

As orientações e informações compartilhadas pelos profissionais de saúde, em especial o enfermeiro, são facilitadoras no processo de aprendizagem para o cuidado e autocuidado, mas quando não realizadas de forma eficaz, tendem a adiar a construção dos novos conhecimentos e, consequentemente, a autonomia das pessoas envolvidas. Assim, cada indivíduo, de acordo com a realidade em que está inserido, busca respostas para suas dúvidas, desenvolvendo formas de atender as necessidades a partir das vivências, de tentativas e erros e pelo conhecimento adquirido no processo do aprenderfazendo.

Contudo, há que se destacar que a comunicação, pautada numa relação de colaboração com paciente e família, na compreensão de suas preocupações e problemas e no incentivo para agir, é uma ferramenta valiosa para os enfermeiros fornecerem suporte informativo e emocional, com vistas a favorecer a adaptação e a autonomia. ${ }^{12}$

O apoio familiar como potencializador do cuidado e da adaptação

A confecção de um estoma se caracteriza como uma estratégia para manutenção da vida, da qual decorrem várias modificações no contexto de vida da pessoa estomizada e de seus familiares. ${ }^{4,13}$ Após a colostomia o 
paciente confronta-se com 0 estranhamento frente as mudanças na apresentação do seu corpo, materializadas na bolsa aderida a pele. ${ }^{14}$ Esta alteração poderá ocasionar dificuldades de interação como o meio em que vive e com a própria família, levando, por vezes, ao isolamento social. ${ }^{15}$

O medo e a insegurança com relação ao funcionamento da colostomia durante as atividades rotineiras foram revelados pelos participantes do estudo, culminando na necessidade de refletir sobre si e o modo de viver diante das dificuldades, como versa a fala a seguir:

Eu não saía de casa. Se estou com a bolsa cheia de fezes, estou caminhando e estoura, como é que eu vou fazer? É complicado. Então eu ficava em casa! Com o tempo fui pegando o jeito. Agora vou a baile, vou a tudo. Mas para conseguir isso demorou. Minha esposa insistia, queria que eu saísse, mas era complicado. Demorou! (P3)

Ao vivenciar o processo de saúdedoença e a necessidade de viver com uma colostomia, a pessoa, além de aprender a lidar com o estoma, precisa ressignificar sua relação com o próprio corpo $^{14}$, demandando um novo tipo de cuidado ${ }^{15}$ e novas formas de ver-se no contexto das relações interpessoais e em sociedade. Nesse processo de adaptação percebe-se como imprescindível o apoio e o suporte da família.

A colaboração da família como suporte emocional e respaldo na realização dos cuidados à pessoa estomizada mostra-se singular e de fundamental importância, pois a mesma conhece as peculiaridades, os hábitos, as preferências e as vulnerabilidades do seu familiar, proporcionando fortalecimento e segurança em relação ao cuidado em si, como pode ser evidenciado nas falas a seguir:

A pessoa que está do nosso lado tem que ajudar, para gente não se sentir tão sozinho. Acho que o importante é o companheirismo. A gente precisa de uma pessoa disposta a nos ajudar a enfrentar essa situação do lado da gente. (P3)

É muito importante também ter a família ao lado, os cuidados trazidos por ela facilitam a adaptação. (P1)

A família nesse momento é fundamental, como apoio e ajuda nos cuidados. (P4)

A aceitação e adaptação do paciente a sua nova condição de vida é influenciada por fatores internos, como também, pelo suporte e apoio familiar a ele atribuído. A família, considerada fonte de amparo e cuidado, quando envolvida no processo terapêutico, contribui para que o paciente estabeleça uma perspectiva otimista em relação a sua maneira de viver com a colostomia, ${ }^{11}$ favorecendo a transição entre os desafios que se apresentam e o restabelecimento de uma vida dita como "normal".

Contudo, as dificuldades em manter um cotidiano estável em decorrência das imprevisibilidades relacionadas à colostomia, tendem a 


\section{IOURNALOF

tornar a vida dos pacientes sem garantia de controle total, o que gera preocupação no que tange a vida familiar e social. ${ }^{3} \mathrm{As}$ dificuldades em desenvolver 0 cuidado a pessoa estomizada e a limitação de fontes de ajuda e suporte, pode colocar 0 paciente e a família diante de fatores que restrinjam a capacidade de enfrentamento das adversidades. ${ }^{16}$

Assim, o papel da família, expresso nas diversas formas de cuidado, torna-se fundamental para a pessoa com colostomia, pois ao fortalecer a autoestima e a autoconfiança, contribui para uma adaptação saudável, refletindo-se em melhora na qualidade de vida. ${ }^{17}$

\section{As possibilidades e limitações no uso do vídeo educativo}

As estratégias de educação em saúde exigem a utilização de uma abordagem organizada, de modo que as pessoas possam satisfazer suas necessidades de cuidado e autocuidado específicos. Para isto, as ferramentas educativas utilizadas devem passar por algumas avaliações, com vistas a sustentar e comprovar sua eficácia para utilização no cotidiano da prática assistencial.

Ao apresentar o vídeo educativo aos participantes do estudo, os mesmos o avaliam como um recurso eficiente para o processo de orientações dos aspectos inerentes ao cuidado e autocuidado do estoma, independente da situação que conduz a sua confecção. Contudo, destacam que o vídeo precisa estar associado a algumas ações práticas, relacionadas à experimentação do fazer, para garantir a apreensão da totalidade de informações necessárias para realizar o cuidado, como evidenciado nas falas a seguir:

É para dar uma dica mesmo, pois nada melhor do que a prática. Porque de início, uma coisa que a gente nunca fez, é bem difícil de fazer. $O$ vídeo dá uma base mais ou menos do que tem que ser feito, mas a prática é que vai realçar o conhecimento de tudo (F1)

A melhor forma de ensinar é com a prática. A prática é melhor do que a teoria, ao meu ver. Penso que se fosse só pelo vídeo eu não aprenderia, teria que ser as duas coisas associadas, teoria $e$ prática. (P1)

Eu acho que o vídeo, de início, ajuda bastante. Claro que com a prática, alguém pegando $o$ material $e$ demonstrando de verdade fica mais fácil. (F2)

A possibilidade de associar a teoria, ou seja, as orientações verbais e demonstrações presentes no vídeo, à prática da execução do procedimento in loco, preferencialmente com supervisão do enfermeiro, favorece a assimilação e a aprendizagem. Estabelecer a integração entre as dimensões teóricas e práticas no processo educativo são considerados ingredientes essenciais de um programa de ensino, principalmente quando se trata de procedimentos e ações específicas de cuidado. ${ }^{1}$

Incentivar o desenvolvimento de habilidades manuais, com vistas a facilitar o cuidado e o autocuidado com o estoma e a bolsa coletora, por meio 
de ações educativas efetivas, considerando as singularidades dos pacientes e de seus familiares, pode contribuir significativamente para cuidado que será ofertado no domicílio. Ademais, os participantes consideram que a utilização do vídeo em questão nos processos educativos exerce maior influência quando inseridos precocemente, ou seja, no período pré-operatório e pósoperatório imediato.

Ver o vídeo e ter orientações no início facilitaria muito, eu vim para casa sem orientação nenhuma. (P3)

Se tivesse mostrado o vídeo no início, eu não teria passado tanto trabalho, pois teria uma noção de como fazer. (P1)

De início ajuda, sim. Agora, nesse momento, eu assistindo ao vídeo não me ajudou, pois eu já me virei para aprender a cuidar. Se fosse no começo, seria ótimo! Se a gente saisse do hospital $e$ assistisse, sim, seria útil. Agora, depois de tempo, já não ajuda. (F3)

A educação em saúde necessita ser iniciada no período pré-operatório e, quando realizada de maneira eficaz, pode contribuir para minimizar as angústias antes e após o procedimento cirúrgico. ${ }^{18} \quad$ Nesse sentido, considerando que para providenciar os cuidados com o estoma, pacientes e familiares precisam receber orientação e apoio contínuos, estes devem começar no pré-operatório e seguir durante a internação, sendo direcionados ao cuidado no domicílio. ${ }^{19}$
Portanto, as

estratégias utilizadas para este fim necessitam estar voltadas a atender as peculiaridades do público-alvo e as necessidades de cuidado e autocuidado apresentadas. Com relação ao vídeo educativo utilizado nesse estudo, a linguagem, a dinâmica e o tempo de duração foram mencionados pelos participantes como facilitadores do processo educativo.

A linguagem do vídeo é clara, bem clara. Tem uma forma bem simples, e bem fácil entender. (F1)

Eu achei a dinâmica do vídeo boa, ele mostra o básico e ficou bem claro. Não acho que faltou alguma coisa, deu para saber um pouquinho de cada coisa, da alimentação, da troca da bolsa e dos cuidados. Deu bem para orientar, foi bom e ficou claro! (F2)

O tempo do vídeo é bom, porque explicou bem as coisas. Foi organizado de forma simples $e$ adequado. Vale em qualquer situação, independente de ser por câncer ou não. (P4)

A produção audiovisual, por utilizar uma metodologia que alia informação visual e auditiva, de maneira dinâmica e que estimula a aprendizagem pelo poder da imagem, é considerada importante para o incremento tecnológico educativo na assistência de enfermagem, bem como, um excelente recurso de comunicação e aprendizagem. ${ }^{7}$ Ademais, permite viabilizar o acesso a várias informações organizadas de 


\section{IOURNALOF

modo a atender as diversas necessidades do paciente e de sua família, fazendo com que estes tenham participação ativa no processo de saúde doença. ${ }^{6}$

Isto posto, torna-se importante destacar um estudo que desenvolveu material com recursos de aprendizagem baseado em vídeo, voltado para cuidadores de crianças portadoras de colostomia, e avaliou sua eficácia em termos de conhecimento e habilidade alcançada. Os resultados comprovaram que o vídeo foi eficaz para aumentar o conhecimento e a habilidade dos cuidadores. ${ }^{18} \mathrm{Tal}$ resultado corrobora o encontrado na presente investigação e sinaliza para a aplicabilidade dessa tecnologia na prática assistencial da enfermagem.

No contexto da educação em saúde voltada ao preparo para a alta hospitalar, o enfermeiro, como agente facilitador desse processo pode colaborar para que os indivíduos adquiram segurança e desenvolvam habilidades para a realização do cuidado e preservação da autonomia. Tendo em vista que o cuidado e o ensino são processos fundamentais na prática da enfermagem, a utilização do vídeo educativo constitui-se em uma forma de ampliar e fortalecer a assistência aos pacientes colostomizados e seus familiares.

\section{CONSIDERAÇÕES FINAIS}

O estudo possibilitou conhecer como os pacientes e seus familiares aprenderam a cuidar e a manejar o estoma. A falta de orientações no ambiente hospitalar evidencia uma lacuna nas estratégias de educação em saúde utilizadas pelos profissionais no momento da alta, tanto aos familiares como à pessoa com colostomia. Dessa forma, é válido propor momentos de sensibilização a esses profissionais e espaços de educação continuada para o desenvolvimento de habilidades que visem o planejamento da alta do paciente recém colostomizado.

$\mathrm{Na}$ realidade vivenciada pelos participantes do estudo, percebe-se as dificuldades advindas da confecção do estoma e da necessidade do uso da bolsa coletora. 0 apoio por parte dos familiares é considerado essencial para adaptação e aceitação, recuperação da autoestima, favorecendo o retorno as atividades sociais e de trabalho e a qualidade de vida.

Quanto à tecnologia educativa utilizada no estudo, conclui-se que o vídeo tem validade educativa também para pacientes com colostomia por causas não oncológicas e seus familiares. Nesse sentido, mostra-se útil desde que seja apresentado precocemente ao público alvo, ou seja, no pós-operatório imediato, antes da alta hospitalar, como reforço às orientações recebidas da equipe de saúde, mas não substituindo ou dispensando-as. Ainda, ressalta-se a importância de que o uso da tecnologia educativa audiovisual esteja associado às demonstrações práticas e ao incentivo do manuseio dos materiais utilizados na higienização, na aderência da bolsa coletora e nos cuidados com a pele, estimulando os pacientes e seus familiares a realizarem os procedimentos.

Os resultados do presente estudo demonstram que o vídeo educativo oferece subsídios que podem auxiliar o 
ISSN 2236 - 1987

planejamento de estratégias de educação em saúde a serem utilizadas pelos enfermeiros, com vistas a potencializar a autonomia e a qualidade de vida das pessoas estomizadas e, consequentemente, de suas famílias.

Como limitações do estudo destaca-se a amostra restrita a apenas um grupo focal, formado por pacientes com colostomia e sua família, não sendo possível a realização de um segundo grupo, uma vez que os participantes não aderiram ao convite. Considerando que a ileostomia é um tipo de estoma de eliminação intestinal, para o qual os cuidados se assemelham com os da colostomia, a inclusão de pacientes com essas características pode constituir um novo grupo focal e potencializar a avaliação do vídeo.

\section{REFERÊNCIAS}

1 Smeltzer SC, Bare BG. Brunner \& Suddarth: tratado de enfermagem médico-cirúrgica. $13^{\mathrm{a}}$ ed. Rio de Janeiro: Guanabara Koogan; 2015.

2 Cunha RR, Ferreira AB, Backes VMS. Características sócio-demográficas e clínicas de pessoas estomizadas: revisão de literatura. Revista estima [Internet]. 2013[acesso em $2017 \mathrm{dez}$ 06];11(2). Disponível em: https: / /www.revistaestima.com.br/in dex.php/estima/article/view/327/0

3 Sarabi N, Navipour H, Mohammadi E. Relative tranquility in ostomy patients' social life: a qualitative content analysis. World journal of surgery [Internet]. 2017[cited 2017 June 13];41(8):2136-42. Available from: https://www.ncbi.nlm.nih.gov/pubm ed/28321552

4 Mota MS, Gomes GC, Petuco VM. Repercussões no processo de viver da pessoa com estoma. Texto \& contexto enferm [Internet]. 2016[acesso em 2017 abr 10]; 25(1):e1260014. Disponível em: http: / /www.scielo.br/pdf/tce/v25n1/ pt_0104-0707-tce-25-01-1260014.pdf

5 Ardigo FS, Amante LN. Conhecimento do profissional acerca do cuidado de enfermagem à pessoa com estomia intestinal e família. Texto \& contexto enferm [Internet]. 2013[acesso em 2017 abr 10];22(4):1064-71. Disponível em:

http://www.scielo.br/pdf/tce/v22n4/ 24.pdf

6 Razera APR, Buetto LS, Lenza NFB, Sonobe HM. Vídeo educativo: estratégia de ensino-aprendizagem para pacientes em tratamento quimioterápico. Cienc cuid saúde [Internet]. 2014[acesso em $2017 \mathrm{abr}$ 10];13(1):173-8. Disponível em: http://www.periodicos.uem.br/ojs/in dex.php/CiencCuidSaude/article/view /19659

7 Ikeda ALC, Cruz FBJ, Rosa LM, Anders JC, Radünz V, Fermo VC. Vídeo educativo na fase pré-transplante de células-tronco hematopoiéticas. Rev enferm UFSM [Internet]. 2016[acesso em 2017 abr 10];6(4):507-17. Disponível em: https://periodicos.ufsm.br/reufsm/ar ticle/view/21520

8 Rosa BVC. Desenvolvimento e validação de um vídeo educativo para famílias de pessoas com colostomia por câncer [dissertação]. Santa Maria (RS): 
Universidade Federal de Santa Maria; 2015.

9 Bauer MW, Gaskell G. Pesquisa qualitativa com texto, imagem e som: um manual prático. $13^{\mathrm{a}}$ ed. Petrópolis: Vozes; 2015.

10 Bardin L. Análise de conteúdo. $4^{\mathrm{a}}$ ed. São Paulo: Edições 70; 2011.

11 Sousa CF, Brito DC, Branco MZPC. Depois da colostomia...vivências das pessoas portadoras. Enferm foco (Brasília) [Internet]. 2012[acesso em 2017 jun 13];3(1):12-5. Disponível em:http://revista.cofen.gov.br/index .php/enfermagem/article/viewFile/2 $13 / 134$

12 Moraes JT, Silva AE, Silva MDM, Guimarães RO, Ferraz GB. A percepção de cirurgiões sobre o cuidado em estomias. Journal of health scienci [Internet]. 2017[acesso em 2017 jun 13];19(1):14-8. Disponível em: http: / / pgsskroton.com.br/seer/index. $\mathrm{php} / \mathrm{JHealthSci} /$ article/view/3211/35 09

13 Tao $H$, Songwathana $P$, Isaramalai SA, Wang Q. Supportive communication to facilitate chinese patients' adaptation to a permanent colostomy: a qualitative case study approach. Gastroenterol nurs [Internet]. 2016[cited 2017 June 17];39(5):366-75. Available from: https://www.ncbi.nlm.nih.gov/pubm ed/27684635

14 Marques ADB, Amorim RF, Landim FLP, Moreira TMM, Branco JGO, Morais $\mathrm{PB}$, et al. Consciência corpórea de pessoas com estomia intestinal: estudo fenomenológico. Rev bras enferm [Internet]. 2018[acesso em $2018 \mathrm{fev}$ 13];71(2):418-24. Disponível em: http://www.scielo.br/pdf/reben/v71 n2/pt_0034-7167-reben-71-02-

0391.pdf

15 Mota MS, Gomes GC. Mudanças no processo de viver do paciente estomizado após a cirurgia. Rev enferm UFPE on line [Internet]. 2013[acesso em 2017 jun 13];7(12):7074-81. Disponível em: https://periodicos.ufpe.br/revistas/r evistaenfermagem/article/view/1237 $8 / 15131$

16 Rosa BVC, Girardon-Perlini NMO, Begnin D, Rosa N, Stamm B, Coppetti LC. Resiliência em famílias de pessoas portadoras de colostomia por câncer: um olhar a partir do sistema de crenças. Ciênc cuid saúde [Internet]. 2016[acesso em 2017 jun 13];15(4):723-30. Disponível em:http://periodicos.uem.br/ojs/ind ex.php/CiencCuidSaude/article/view/ 34739/18459

17 Mendes AS, Ribeiro MA, Santana ME. Qualidade de vida de indivíduos com estomias intestinais. J nurs health [Internet]. 2013[acesso em $2018 \mathrm{fev}$ 13];3(1):126-35. Disponível em: https://periodicos.ufpel.edu.br/ojs2/ index.php/enfermagem/article/view/ $3709 / 3020$

18 Rorato AMRS, Lima SBS, Silveira LD, Santiago AS. O uso da internet e do lúdico como ferramentas para a educação em saúde nas orientações perioperatórias. Rev saúde digital e tecnologias educacionais [Internet]. 2016 ago/dez[acesso em 2017 jun 13];1(2):36-43. Disponível em:periodicos.ufc.br/resdite/article/ download/19593/30261

19 Dabas H, Sharma KK, Joshi P, Agarwala S. Video teaching program on management of colostomy: evaluation 


\section{NURSING AND}

of its impact on caregivers. J indian assoc pediatr surg [Internet]. 2016[cited 2017 June 13];21(2):54-6. Available from:

http://www.jiaps.com/text.asp?2016 /21/2/54/17693

Data de submissão: 12/06/2018

Data de aceite: $22 / 07 / 2018$

Data de publicação: 29/10/2018 